\title{
Effectiveness of Balance Exercises on Postural Control and Quality of Life in Patients with Lumbar Discopathy
}

\author{
Sahin Karpuz ${ }^{1}(\mathbb{D})$, Umut Bahcaci ${ }^{2}$ (D) , Seval Kutluturk ${ }^{3}(\mathbb{D})$ Tugba Kuru Colak $^{4}(\mathbb{D})$ \\ ${ }^{1}$ Ornek Medical Center, Istanbul, Turkey. \\ ${ }^{2}$ Gayrettepe Florence Nightingale Hospital, Istanbul, Turkey. \\ ${ }^{3}$ Assistant Professor, Department of Physical Therapy and Rehabilitation, School of Health Sciences, Istanbul Medipol University, Istanbul, Turkey. \\ ${ }^{4}$ Associated Professor, Department of Physiotherapy and Rehabilitation, Faculty of Health Sciences, Marmara University, Istanbul, Turkey. \\ Correspondence Author: Seval Kutluturk \\ E-mail: skutluturk@medipol.edu.tr \\ Received: $18.02 .2020 \quad$ Accepted: 02.01 .2021
}

\begin{abstract}
Objective: Lumbar discopathy is a common problem that affects musculoskeletal system. Many treatment modalities are in use for patients with lumbar discopathy. Balance exercises could be important for the lumbar discopathy due to the affected musculoskeletal system. This study was planned to investigate the effect of balance exercises on postural control and quality of life for lumbar discopathy.

Method: A total of 81 patients were divided into two as the intervention and the control groups. Therapeutic ultrasound, transcutaneous electrical nerve stimulation (TENS), hotpack and therapeutic exercises were applied to all patients 5 times a week during thirty sessions. Additionally, the intervention group received balance exercises. Pain (Visual Analog Scale), disability (Oswestry Disability Index), quality of life (Short Form-36) and postural control (Libra ${ }^{\circledR}$ ) have been evaluated by same physiotherapist before and after the treatment.

Results: Statistically significant differences were found between the groups comparing pain, disability and postural control parameters ( $p<0.05$ ). In the between group comparisons of the mean changes of the 'Quality of Life' assessment parameters, no significant differences were obtained between the intervention and control groups ( $p>0.05$ ), except the 'physical role' parameter in favor of the control group ( $p=0.04)$.

Conclusion: This study demonstrated that physiotherapy modalities improve pain, disabiliy, quality of life and postural control parameters in patients with lumbar discopathy but adding classic balance exercises in physiotherapy treatment, do not have a remarkable effect in patients with lumbar discopathy.
\end{abstract}

Keywords: Lumbar discopathy, balance exercises, postural control, quality of life, physiotherapy

\section{INTRODUCTION}

Lumbar discopathy (LD) is a common health problem that causes low back pain (LBP) in most of the population. Most of adult population (80-85\%) experience LBP at least once in their life. LD's constitute $64 \%$ of chronic LBP that mostly affects daily life activities negatively $(1,2)$

Many non-pharmacological therapy options such as manual therapy, exercise approaches, electrotherapy, massage, acupuncture and cognitive behavioral therapy are in use. Recent review study recommends most of these therapies when provided as a part of multimodal package (3). Appropriate exercise approaches have benefit in patients with LD. After assessment of the patient, suitable exercises programs could be prescribed such as stretching and strengthening exercises, core exercises or stabilization exercises (4-6). Besides that; patients should be informed about correct posture in order to prevent their mistakes and recurrence problems and to ensure correct body mechanics in daily life activities on the basis of ergonomic principles $(7,8)$.
Balance and postural control disorders have explained widely in literature for patients with LBP. When the postures of the patients with LD were examined, the existence of flexed vertebral column, decreased lumbar lordosis, flexion position of the affected lower extremity and antalgic gait could be most seen (9). Balance problems in patients with LD are caused by pain, uneven distribution of load in the lower extremities, and muscle weakness. This asymmetry in the load distribution and accompanying pain, affects the proprioceptive input and forms the basis of balance problems and leads to loss of postural control. These problems negatively affect the individual's independence and mobility in daily life activities $(10,11)$.

Most of the studies only evaluate balance or postural control in patients with chronic LBP or LD. Our study aims to investigate the effect of balance exercises on postural control and quality of life in addition to physiotherapy approaches in patients with LD. 


\section{METHODS}

This experimental study was designed as non-randomized controlled and carried out in a physiotherapy department after the approval of institute ethics committee (Ethics Committee of Marmara University, Institute of Health Sciences, Reference No: 16.01.2014-4).

The patients enrolled with LD aged between 18-70 years old who were admitted Physical therapy and rehabilitation department of 'Median Tip Merkezi' in Istanbul, in the 6-month period in 2014. Patients who agreed to participate in the study filled an informed consent form. The including criteria were; diagnosis of LD by MRI, existing low back pain at least 3 months, existence of bulging or protruding discs, being able to understand and participate in program. The patients were excluded if they have extruded or sequestered disc, scoliosis, neurological sequelae, cardiac pacemaker or pregnancy. Patients who had spine or lower extremity surgery, rheumatologic, congenital, vestibular, neurologic diseases that could cause balance problems, were also excluded.

At first, the study enrolled 102 patients. Fifteen patients didn't meet the including criteria and one patient refused to participate. Rest of 86 patients were allocated into intervention group (IG) and control group (CG) by $1: 1$ allocation ratio. The allocation was made by sequence of incoming patients.

\subsection{Procedures}

Patients in both groups received the conventional physiotherapy procedure for 30 sessions (5 sessions per week, 6 weeks). Additionally, IG received balance exercises. The conventional physiotherapy procedure consists of Ultrasound (US) with frequency of $1 \mathrm{MHz}$ and intensity of $1 \mathrm{~W} / \mathrm{cm}^{2}$ for $10 \mathrm{~min}$; Transcutaneous Electrical Nerve Stimulation (TENS) with a frequency of $60-80 \mathrm{~Hz}$ and duration of $50-100 \mu \mathrm{s}$ in conventional mode for $20 \mathrm{~min}$; Hotpack with TENS for $20 \mathrm{~min}$; and exercises including abdominal strengthening, lumbal traction and squat exercises that the patients waited 5 seconds at the end of each exercise and repeat each exercise 10 times.

IG received two classical balance exercises in addition to classical physiotherapy procedure. These are 'single leg stance exercise' determined as static balance exercise and 'tandem gait' determined as dynamic balance exercise. In the single leg stance exercise, subjects were asked to stand on one foot as long as they could, with their eyes open. In the tandem gait, subjects were asked to walk a total of 5 laps on a 2-meter-long line with the heel of the front foot touching the fingertip of the back foot. Patients were evaluated baseline and after six weeks of treatment. Evaluations were performed by a consider researcher who knew group which the cases were within the study. It was the same physiotherapist who did the evaluation and treatment.

\subsection{Outcome measures}

Visual Analog Scale (VAS) assesses pain subjectively using a $0-10$ centimeters $(\mathrm{cm})$ scale, where 0 indicates "no pain" and 10 indicate "worst pain" (12).

Oswestry Disability Index (ODI) is reliable and valid tool assesses the permanent functional disability. ODI contains 10 items related to limitations in daily life activities, with 0 (no disability) - 5 (severe disability) point scale (13). Turkish version of the tool is in use (14).

Short form 36 (SF-36) consists 36 items and assesses the quality of life (QoL) level. It has 8 sub-parameters as physical function, physical role, pain, general health, vitality, social function, emotional role difficulty and mental health. Each sub-parameter is scored on a scale of 0 to 100 , where 0 is the lowest and 100 is the highest score (15). Reliable and valid Turkish version were used (16).

Libra (Easytech, Italy, 2013) was used to assess the postural balance. The subjects were asked to try to stay on the device in the form of a balance board, on both feet and without any support. Displacement of the body center of gravity on the virtual screen was controlled by the patient without slipping to the right or left. The evaluation consisted of 3 repetitions, each last 1 minute. The average score of the 3 repetition was recorded $(17,18)$.

\subsection{Statistical analysis}

SPSS (Statistical Package for Social Sciences Inc. Chicago, IL, USA) Version 22.0 was used for data analysis. The sample size was calculated by using a previous study, which mentioned the impact of trunk balance exercises in chronic low back pain (19). The mean and standard deviation data of the VAS parameter were used with a power (1-type II error) of 0.90 and a Type I error of 0.05 . Therefore, it was aimed to recruit at least 37 participants per group. In total, with a dropout rate of $20 \%$, it was estimated that 44 patients would be recruited in each group. Kolmogorov-Smirnov test was used for the compatibility of the data with normal distribution. Mean values, standard deviations and the percentage of total for each variable of interest were calculated. Qualitative demographic data in groups was examined by Chi-square test. Wilcoxon $\mathrm{T}$ Test was used to determine the changes after the treatment and Mann-Whitney $U$ Test was used to compare the difference between groups. Significance level was set at $p \leq 0.05$.

\section{RESULTS}

Total of 86 patients were recruited to the study. Two patients in IG and three patients in CG were excluded because they could not complete all sessions. Therefore 81 patients (IG:41 and CG:40) completed the sessions (Figure 1). The demographic characteristics of groups was similar at baseline (Table 1).

There was no significant difference in the severity of pain in between group comparisons ( $p=0.05$ ) while it was significantly 
better in each group before and after the treatment $(p<0.01)$ (Table 2).

Significant improvements were obtained in ODI results in each group between before and after the treatment $(p<0.01)$. But there was no significant difference in between group comparisons for the ODI results $(p=0.99)$ (Table 2).

SF-36 with the sub-parameters of physical function $(p<0.01)$, physical role $(p<0.01)$, pain $(p<0.01)$, vitality $(p=0.05)$, social function $(p=0.01)$ and mental health $(p=0.04)$ showed significant difference in CG; physical function $(p<0.01)$, pain $(p<0.01)$ and general health $(p=0.03)$ showed significant difference in IG, before and after treatment. In between group comparisons of the sub-parameters of the SF-36, no significant differences were obtained between the IG and CG ( $p>0.05)$, except 'physical role' $(p=0.04)$ parameter in favor of the CG (Table 2).

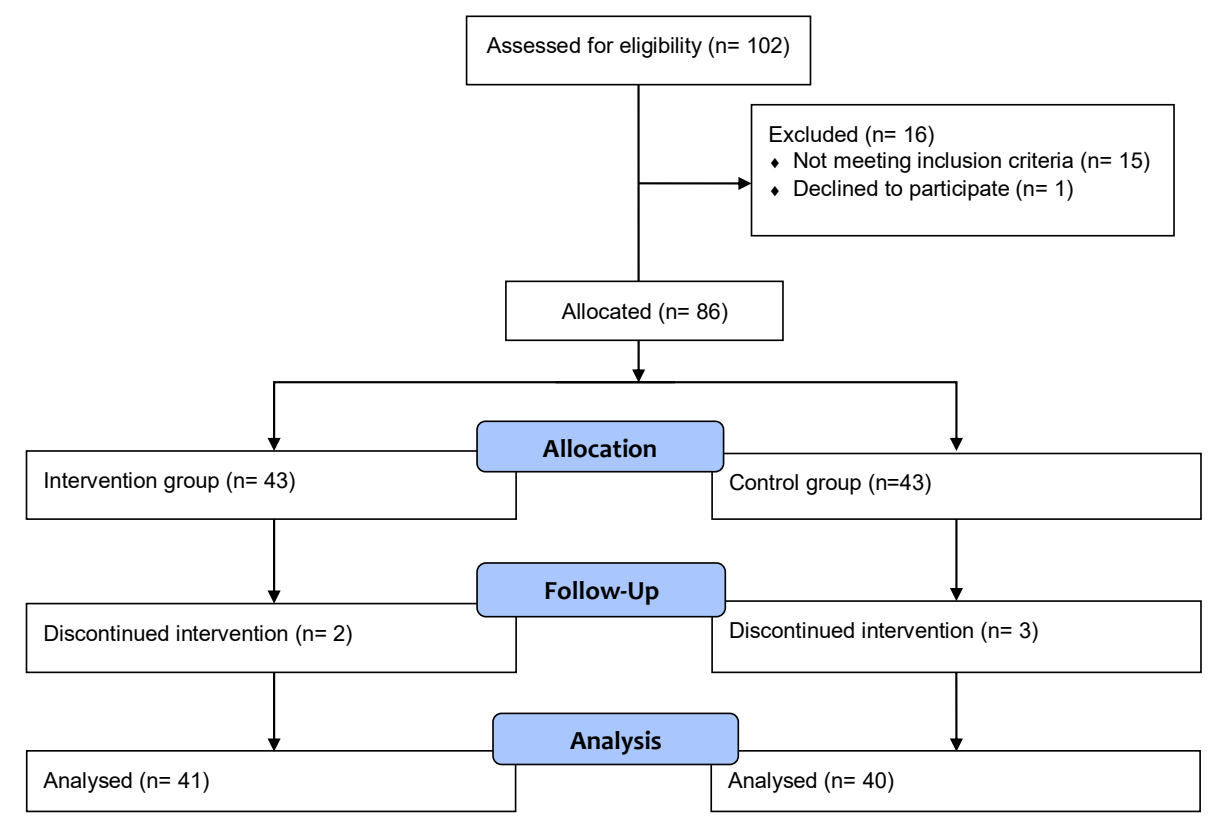

Figure 1. Flow chart

Table 1. Baseline and demographic characteristics

\begin{tabular}{|c|c|c|c|c|c|}
\hline & & $\begin{array}{l}\text { Control } \\
\text { Group } \\
(n=41)\end{array}$ & $\begin{array}{l}\text { Interventional Group } \\
(\mathrm{n}=40)\end{array}$ & $\begin{array}{l}\text { Total } \\
(n=81)\end{array}$ & $\begin{array}{l}P \\
\text { value }\end{array}$ \\
\hline \multicolumn{2}{|l|}{ Age (year) mean $\pm S D$} & $48.59 \pm 10.49$ & $47.5 \pm 12.29$ & $48.05 \pm 11.36$ & 0.91 \\
\hline \multicolumn{2}{|l|}{ Height $(\mathrm{cm})$ mean $\pm S D$} & $163.6 \pm 8.95$ & $163.55 \pm 7.85$ & $163.58 \pm 8.37$ & 0.81 \\
\hline \multicolumn{2}{|l|}{ Weight (kg) mean $\pm S D$} & $78.22 \pm 12.73$ & $76.13 \pm 11.89$ & $77.19 \pm 12.29$ & 0.35 \\
\hline \multicolumn{2}{|l|}{ BMI $\left(\mathrm{kg} / \mathrm{m}^{2}\right)$ mean $\pm S D$} & $29.24 \pm 5.02$ & $28.53 \pm 4.55$ & $28.89 \pm 4.78$ & 0.42 \\
\hline \multicolumn{2}{|c|}{ Daily sitting time (hour) mean $\pm S D$} & $4.56 \pm 3.08$ & $4.26 \pm 3.29$ & $4.41 \pm 3.17$ & 0.46 \\
\hline \multirow[t]{2}{*}{ Gender $n(\%)$} & Male & $14(34.15)$ & $10(25)$ & $24(29.63)$ & \multirow[t]{2}{*}{0.26} \\
\hline & Female & $27(65.85)$ & $30(75)$ & $57(70.37)$ & \\
\hline \multirow[t]{2}{*}{ Occupational status n(\%) } & Working & $16(39.02)$ & $14(35)$ & $30(37.04)$ & \multirow[t]{2}{*}{0.44} \\
\hline & Non working & $25(60.98)$ & $26(65)$ & $51(62.96)$ & \\
\hline \multirow[t]{4}{*}{ Educational status $\mathrm{n}(\%)$} & No education & $4(9.75)$ & $3(7.5)$ & $7(8.64)$ & \multirow[t]{4}{*}{0.47} \\
\hline & Primary & $29(70.73)$ & $24(60)$ & $53(65.43)$ & \\
\hline & Secondary & $6(14.63)$ & $7(17.5)$ & $13(16.04)$ & \\
\hline & University & $2(4.87)$ & $6(15)$ & $8(9.87)$ & \\
\hline \multirow{2}{*}{$\begin{array}{l}\text { Stage of discopathy } \\
n(\%)\end{array}$} & Bulging & $18(43.9)$ & $16(40)$ & $34(41.98)$ & \multirow[t]{2}{*}{0.45} \\
\hline & Protrusion & $23(56.1)$ & $24(60)$ & $47(58.02)$ & \\
\hline
\end{tabular}

BMI: Body Mass Index, SD: Standard Deviation 
Table 2. Study outcomes

\begin{tabular}{|c|c|c|c|c|c|c|c|c|}
\hline & & \multicolumn{2}{|l|}{$\begin{array}{l}\text { Control Group } \\
\mathrm{N}=41\end{array}$} & & \multicolumn{3}{|c|}{ Intervention group } & P value \\
\hline & & $\begin{array}{l}\text { Before Treatment } \\
\text { X } \pm \text { SD }\end{array}$ & $\begin{array}{l}\text { After } \\
\text { Treatment } \\
\text { X土SD }\end{array}$ & P value & $\begin{array}{l}\text { Before } \\
\text { Treatment } \\
\text { X土SD }\end{array}$ & 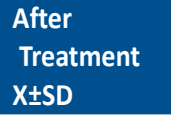 & $P$ value & $\begin{array}{l}\text { (Between Group } \\
\text { Comparison) }\end{array}$ \\
\hline \multicolumn{2}{|c|}{ VAS (Pain, 0 to $10 \mathrm{~cm}$ ) } & $5.46 \pm 2.42$ & $4.41 \pm 2.39$ & $<0.01^{*}$ & $6.28 \pm 2.03$ & $3.9 \pm 2.27$ & $<0.01 *$ & 0.05 \\
\hline \multicolumn{2}{|c|}{ ODI (Disability) } & $22.61 \pm 8.43$ & $14.17 \pm 6.84$ & $<0.01 *$ & $23.15 \pm 6.32$ & $14.23 \pm 7.26$ & $<0.01 *$ & 0.99 \\
\hline \multicolumn{2}{|c|}{ Libra (Postural Control) } & $8.47 \pm 3.24$ & $6.7 \pm 2.31$ & $<0.01^{*}$ & $9.04 \pm 3.33$ & $6.46 \pm 2.7$ & $<0.01^{*}$ & 0.17 \\
\hline \multirow{8}{*}{ 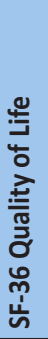 } & Physical Function & $65.12 \pm 21.58$ & $76.46 \pm 16.93$ & $<0.01^{*}$ & $61.13 \pm 18.76$ & $72.63 \pm 15.81$ & $<0.01^{*}$ & 0.6 \\
\hline & Physical Role & $25.61 \pm 32.35$ & $45.73 \pm 36.62$ & $<0.01^{*}$ & $21.25 \pm 27.47$ & $28.75 \pm 35.15$ & 0.1 & $0.04^{* *}$ \\
\hline & Pain & $37.56 \pm 21.42$ & $55.12 \pm 15.99$ & $<0.01 *$ & $41.75 \pm 18.1$ & $52.75 \pm 20.38$ & $<0.01 *$ & 0.26 \\
\hline & General Health & $59.02 \pm 20.5$ & $62.8 \pm 19.5$ & 0.15 & $50 \pm 17.9$ & $55.5 \pm 18.46$ & $0.03^{* *}$ & 0.44 \\
\hline & Vitality & $52.07 \pm 20.49$ & $58.88 \pm 20.16$ & $0.05^{* *}$ & $41.63 \pm 18.72$ & $44.88 \pm 22.69$ & 0.42 & 0.31 \\
\hline & Social Function & $54.57 \pm 23.01$ & $65.55 \pm 23.01$ & $0.01 * *$ & $57.19 \pm 24.98$ & $59.69 \pm 24.1$ & 0.54 & 0.25 \\
\hline & Emotional Role & $40.65 \pm 39.1$ & $51.22 \pm 39.52$ & 0.07 & $38.5 \pm 35.04$ & $39.17 \pm 41.27$ & 0.92 & 0.15 \\
\hline & Mental Health & $69.17 \pm 18.27$ & $74.34 \pm 15.85$ & $0.04 * *$ & $61.4 \pm 15.44$ & $63.4 \pm 20.39$ & 0.49 & 0.32 \\
\hline
\end{tabular}

VAS: Visual Analog Scale, ODI: Oswestry Disability Index, SD: Standard Deviation, cm:centimeter, ${ }^{*} p<0.01,{ }^{* *} p \leq 0.05$.

\section{DISCUSSION}

In this study, we aim to evaluate the effects of balance exercises on postural control and quality of life in patients with lumbar discopathy. The results of our study showed that the balance exercises that were selected with conventional therapy did not increase the positive effects of treatment on pain, disability, quality of life and postural control in patients with lumbar discopathy. There are many studies in the literature that is about investigating balance status or postural control in patients with lumbar discopathy or chronic low back pain (19-21). The difference of our study from these studies is to investigate the effectiveness of balance exercises added to the conventional treatment that is included electrotherapy modalities and therapeutic exercise program.

Omokhodion and Sanya found that there is a relationship between sitting time exceeding 3 hours and low back pain in their study (22). In our study, the average daily sitting time of all patients was $4.41 \pm 3.17$ hours and $59.26 \%$ of the patients mentioned that did not walk every day. These results show that recommendations can be given to patients with LD to decrease the sitting time and increase the time of physically active.

Phadke and Yadav examined the effects of balance exercises in patients with chronic low back pain and compared to the pain, functional status, quality of life and balance status of patients between conventional and balance exercises group and conventional physiotherapy group. In this study, they were detected significant difference in all assessment area in both groups, but there was no significant difference between the groups in terms of all assessment results (20). Gatti et al. researched the efficacy of trunk balance exercises for individuals with chronic low back pain in the study. It has been reported that flexibility and balance exercises have no superiority over pain intensity compared to flexibility and strengthening exercises (19). In our study, pain intensity and functional disability of the patients was evaluated with VAS and ODI. Pain intensity and ODI scores of the two groups were similar at the baseline of the study. After the treatment program, pain and ODI scores decreased significantly in both the groups. When the mean of intergroup change in pain and ODI scores were compared, the groups did not have superiority over each other. These results show that balance exercises in addition to conventional treatment are not more effective on pain and functional disability.

Boskovic et al. investigated the effectiveness of conservative treatment in patients with lumbar radiculopathy and to evaluated the quality of life of patients with SF-36. This study reported that is achieved improvements in all parameters related to physical health but there is no significant difference in parameters related to mental health (23). In our study, we found only improvements in physical function and pain parameters of the quality of life in the control and intervention groups.

Tari et al. were used to Libra on patients' balance and postural control status in their studies (24). In our study, postural control was evaluated with Libra, and there were improvements on postural control in both groups. These results suggested that pain and trunk muscle weakness affecting postural control in patients with lumbar discopathy or chronic low back pain can be eliminated with therapeutic exercises in the physiotherapy program.

As a recommendation of this study demonstrated that physiotherapy modalities improve pain, disability, quality of life and postural control parameters in patients with lumbar discopathy. Whereas single leg stance and tandem stance exercises performed as classic balance exercises in physiotherapy treatment, do not have a remarkable effect in patients with lumbar discopathy.

Limitations of our study are that the effects of different balance exercises were not compared, and the effectiveness of conventional approaches and balance exercises could not be examined separately. In the future studies, we recommend 
that different balance exercises be applied at different intensities and durations to examine their effectiveness in the long term.

\section{CONCLUSION}

The results of our study show that classical physiotherapy modalities and therapeutic exercise approaches are effective in patients with lumbar discopathy in terms of pain, disability, quality of life and postural control.

Financial Disclosure: The authors have no financial relationships relevant to this article to disclose.

Funding source: No external funding is available for this manuscript.

Declaration of interest: The authors report no conflicts of interest. The authors alone are responsible for the content and writing of the paper.

\section{REFERENCES}

[1] Hoy D, Brooks P, Blyth F, Buchbinder R. The epidemiology of low back pain. Best Pract Res Clin Rheumatol 2010; 24(6):769781.

[2] Geurts JW, Willems PC, Kallewaard JW, van Kleef M, Dirksen C. The impact of chronic discogenic low back pain: costs and patients' burden. Pain Res and Manag 2018; 2018:4696180.

[3] Maher C, Underwood M, Buchbinder R. Non-specific low back pain. Lancet 2017; 389(10070):736-747.

[4] Owen PJ, Miller CT, Mundell NL, Verswijveren SJJM, Tagliaferri $\mathrm{SD}$, Brisby $\mathrm{H}$, Bowe SJ, Belavy DL. Which specific modes of exercise training are most effective for treating low back pain? Network meta-analysis. Br J Sports Med 2020; 54(21):12791287.

[5] Shahbandar L, Press J. Diagnosis and nonoperative management of lumbar disk herniation. Oper Tech Sports Med 2005; 13:114-121.

[6] Rackwitz B, Limm H, Wessels, Ewert T, Stucki G. Practicability of segmental stabilizing exercises in the context of a group program for the secondary prevention of low back pain. An explorative pilot study. Eura Medicophys 2007; 43:359-367.

[7] Meng K, Peters S, Faller H. Effectiveness of a standardized back school program for patients with chronic low back pain after implementation in routine rehabilitation care. Patient Educ Couns 2017; 100(6):1161-1168.

[8] Traeger AC, Huebscher M, Henschke N, Moseley GL, Lee $\mathrm{H}$, McAuley JH. Effect of primary care-based education on reassurance in patients with acute low back pain: systematic review and meta-analysis. JAMA Intern Med 2015; 175(5):733743.
[9] Schelldorfer S, Ernst MJ, Rast FM, Bauer CM, Meichtry A, Kool J. Low back pain and postural control, effects of task difficulty on centre of pressure and spinal kinematics. Gait Posture 2015; 41(1):112-118.

[10] Karimi N, Ebrahimi I, Kahrizi S. Evaluation of postural balance using the biodex balance systems in subjects with and without low back pain. Pak J Med Sci 2008; 24(3):372-377.

[11] Takla MK. Alterations of static and dynamic balance in patients with lumbar radiculopathy. Bull Fac Phys Ther 2019; 24(1):4955.

[12] Pincus T, Bergman M, Sokka T, Roth J, Swearingen C, Yazici Y. Visual analog scales in formats other than a 10-centimeter horizontal line to assess pain and other clinical data. J Rheumatol 2008; 35(8):1550-1558.

[13] Fairbank JC, Pynsent PB. The Oswestry Disability Index. Spine 2000; 25(22):2940-2952.

[14] Yakut E, Düger T, Öksüz Ç, Yörükan S, Üreten K, Turan D, Fırat T, Kiraz S, Krd N, Kayhan H, Yakut Y, Güler C. Validation of the Turkish version of the Oswestry Disability Index for patients with low back pain. Spine 2004; 29(5):581-585.(Turkish)

[15] Ware JE, Jr., Sherbourne CD. The MOS 36-item short-form health survey (SF-36): I. Conceptual framework and item selection. Med Care 1992; 30(6):473-483.

[16] Koçyigit H, Aydemir Ö, Fisek G, Ölmez N, Memis A. Kısa Form36 (KF-36)'nın Türkçe versiyonunun güvenilirliği ve geçerliliği. İlaç ve Tedavi Dergisi 1999; 12(2):102-106. .(Turkish)

[17] Boccolini G, Brazzit A, Bonfanti L. Using balance training to improve the performance of youth basketball players. Sport Sci Health 2013; 9:37-42.

[18] Lukowicz M, Zalewski P, Bulatowicz I. The impact of laser irradiation on global stability in patients with vertebrobasilar insufficiency: A clinical report. Med Sci Monit 2011; 17(9):517522

[19] Gatti R, Faccendini S, Tettamanti A. Efficacy of trunk balance exercises for individuals with chronic low back pain: A randomized clinical trial. J Orthop Sports Phys Ther 2011; 41(8):542-552.

[20] Phadke S, Yadav P. Efficacy of balance exercises in chronic low back pain. International J Adv Res 2016; 4(7):2066-2068.

[21] Truszczynska A, Dobrzynska M, Trzaskoma Z. Assessment of postural stability in patients with lumbar spine chronic disc disease. Acta of Bioengineering and Biomechanics 2016; 18(4):71-77.

[22] Omokhodion F, Sanya A. Risk factors for low back pain among office workers in Ibadan, Southwest Nigeria. Occup Med 2003; 53:287-289.

[23] Boskovic K, Todorovic-Tomasevic S, Naumovic N. The quality of life of lumbar radiculopathy patients under conservative treatment. Vojnosanit Pregl 2009; 66(10):807-812.

[24] Tari A, Kumar S. The effect of postural stability exercises in benign paroxysmal positional vertigo: Pre-post experimental study. J Indian Assoc Physiother 2017; 11(2):66-70.

How to cite this article: Karpuz S, Bahcaci U, Kutluturk S, Kuru Colak T. Effectiveness of Balance Exercises on Postural Control and Quality of Life in Patients with Lumbar Discopathy. Clin Exp Health Sci 2021; 11: 146-150. DOI: 10.33808/clinexphealthsci.690621 